\title{
Advancing Experiential Learning through Participatory Design
}

\author{
Pavan Inguva ${ }^{1}$, Daniel Lee-Lane ${ }^{1}$, Anastasia Teck ${ }^{1}$, Benaiah Anabaraonye ${ }^{1}$, \\ Wenqian Chen ${ }^{1}$, Umang V. Shah ${ }^{1}$, Clemens Brechtelsbauer ${ }^{1 *}$ \\ ${ }^{1}$ Department of Chemical Engineering, Imperial College London, South Kensington, \\ London SW7 2AZ, United Kingdom
}

\begin{abstract}
Participatory design (PD) as a module development tool offers significant potential to enhance experiential learning courses such as laboratory modules. Involvement of students and other stakeholders results in pre-delivery feedback on module design, implementation strategy, and teaching material. In this study, PD was employed for design and development of a systems control and reaction engineering laboratory project. The nature of stakeholder interaction at various levels was analysed and specific examples for how such an approach improved the development process is presented. Current students provided feedback on how the module was perceived by their peers and participated in developing solutions to make the learning process more inclusive. Senior students and graduate teaching assistants (GTAs) were able to contribute at a higher technical design level. Students were intellectually stimulated by the module design, enhancing the overall teaching and learning process.
\end{abstract}




\section{Introduction}

Student-centric learning is broadly accepted as being advantageous for the learning process and, consequently, learner outcomes (Wright, 2011). These learning and teaching approaches benefit students as it places them in the driver's seat while instructors serve as 'catalysts': students take the initiative and develop into mature and successful learners (Weimer, 2002). Independent enquiry based learning is not only considered pivotal for promoting deep learning, but is also key for the development of professional skills (Amolins et al., 2015) through tasks based on authentic industrial problems (Glassey et al., 2013).

There are several approaches to increase learner centricity, which include e.g. shifting the power dynamics in the classroom, empowering students to shape how the course would be operated in terms of course content, delivery and assessment structure (Tyma, 2009). Active learning, team based learning, collaborative learning, peer learning, and blended learning have been applied in engineering education for some time. These efforts predominantly focus on course delivery and operation, but there is little discussion on the role of student participation in driving changes to curriculum development itself. The few instances with students actively involved in the development of the course content were class room based rather than practical modules (Bovill, 2011). Student participation in planning of module content and delivery methods has usually been limited to providing feedback and pointing out issues with the lesson plan as put forth by the educator. In one case, students were co-opted into curriculum planning committees to contribute to the course design for their medical program by providing current perspectives, in recognition of the generational gap between educators and students (Huppatz, 1996). These cases generally point out the benefits that can be achieved through student involvement, 
such as enhanced learner outcome as well as increased collective and individual student responsibility towards the module and the educators (Bovill, 2011).

Participatory design (PD) combines the expertise of multiple stakeholders to develop a product in a process of co-creation where the various stakeholders are treated as partners so that the final outcome best meets the requirements of all involved (Könings et al., 2014). Various methods have been used to implement PD in relation to consumer products and services. While the use of PD in education has been discussed, it has yet to see widespread application. Applying PD to education means that students collaborate with educators as design partners to shape their learning experience. Although students may lead the design group, they are not learning by self-determination, and are instead on the second highest rung in Bovill's student participation model (Bovill and Bulley, 2011). One of the main advantages of participatory design is that both students and educators are stimulated to reflect on teaching and learning methods, thereby including their points of view into the design process (Könings et al., 2014). The case study presented in this work highlights positive change in the level of student engagement, intellectual stimulation, and ultimately student experience as a result.

\section{Course context}

The chemical engineering teaching laboratories contribute practical modules to the overall curriculum designed on the principles of experiential learning. Details of the "Foundation to Discovery" teaching philosophy and corresponding teaching modules are described elsewhere (Chen et al., 2016). The Knowledge Laboratory is a practical learning module designed for $2^{\text {nd }}$ year chemical engineering students. Students work in groups of 3-4, supported by a GTA and appropriate project briefs. 
The entire module consists of 40 timetabled hours spread over the Autumn and Spring Terms.

Prior to academic year (AY) 2016/2017, the Knowledge Lab followed a structure as outlined in the Prior Module Design Approach section below. The entire module was overhauled for AY 2016/2017 onwards by involving multiple stakeholders within a PD framework. This article presents how PD was applied in the module redesign process using one project as a case study.

\section{Research methodology}

To understand reception of the new module as well as the impact of PD in the design process, focus groups of current students, who were assigned to the project described in this case study and senior students who broadly represent the demographic of the course, were sent an open invitation to leave free text comments on their laboratory experience. The senior students were selected with an approximate 50-50 split with respect to Home/EU and International fee status, a range of ethnicities and both male and female students to achieve a representative sample. In addition, we made use of responses from the Undergraduate Student Online Evaluation (UG SOLE), a survey conducted by the college after each teaching term for feedback on modules and lecturers, details of which are described elsewhere (Chen et al., 2016). Student comments received from the students from SOLE are representative of the entire Knowledge Lab module and not just the project case study discussed.

\section{Prior module design approach}

A conventional module design approach as marked out in red in Figure 1 represents the typical top-down approach that was previously adopted where the educator, as a 
single stakeholder, is driving the module design process. Students validated several key concepts taught during core lecture modules such as separation processes, reaction engineering, thermodynamics, fluid mechanics, and process control.

Reaction engineering and systems control were taught separately through two different projects. The process flow diagrams (PFD) for the equipment used in the two projects are shown in Figure 2.

Senior students' were failing to engage with this approach, labelling it as 'following procedure' and 'boring'. The cognitive and intellectual disengagement from the module is clear from student feedback. A critical evaluation of UG SOLE feedback suggested that

1) students did not feel intellectually challenged by the experiments or the method of delivery,

2) the design of equipment failed to stimulate interest even though it was able to achieve the teaching outcomes, and

3) students were not able to link the experiments with the broader course context and its industrial relevance.

\section{$P D$ based module design}

A PD approach involves bringing together all stakeholders at the design stage in a collaborative setting. In analogy to process control, traditional PD uses a single feedback control mechanism (Figure 3), where the controlled variables are the various aspects of the learning experience and the manipulated variables are the different features of the designed module.

The advanced PD framework developed in this study, incorporates a double feedback mechanism, where the design process itself has also a feedback 
mechanism (Figure 4). The students in the design team anticipate potential problems during the design process based on their past experience or training, and make corrections immediately.

The advanced PD process is detailed in Figure 5, where students took a leading role in project development from Phase B onwards, and teachers assumed the role of the project supervisor. Key is the strong pre-delivery stakeholder feedback during each of the module design stages. In the advanced PD framework, a stakeholder's role is not limited to just providing input into design discussions based on their existing expertise. As they participate in the development, prototyping, and testing activities, their knowledge evolves which facilitates iterative improvement. This paradigm of iterative module design within a PD framework has not been explored significantly thus far in the literature and we believe that such a model strongly enhances the overall teaching quality of the eventual outcome.

\section{Optimisation of a CSTR - a case study of advanced PD}

Phase $A$ - project conception

The role of the module leader was to conceive a project that simultaneously meets the learning objectives and sets the project in an authentic context whilst intellectually stimulating learners. To achieve this, the module leader provided the broad outline for this project and experimental set-up with a multi-variable control system coupled with a CSTR to create an integrated systems control and reaction engineering experiment using standard industrial components. A project brief would define a problem with a clear set of objectives to solve, yet the solution approach and experimental design will be open-ended. Students will be tasked with a project that is structured into 3 'steps' which gradually increase in difficulty and scale. At the 
end of each intermediary steps, students will discuss their results with the supervisor and agree a work plan for the next project step.

During the module conception process issues arising from the old module and what caused them were discussed. This provided an opportunity for stakeholders to contribute possible solution strategies. For instance, the module leader wanted students to enjoy greater freedom in the project. However, both GTAs and senior students cautioned him about the students' ability to cope with too much uncertainty. To satisfy both requirements, the idea of splitting the project into 3 'steps' and involving the GTA in providing more active support during 'step changes' was conceived (Roll-out $\rightarrow$ Conception).

Phase $B$ - experimental design

The task for process design was assigned to two GTAs with expertise directly relevant to the project: one's research area is in artificial intelligence $(\mathrm{Al})$, which contributed significantly to the design of control system, the other GTA had prior professional expertise as a process design engineer. Continuous dialogue and interaction between the GTAs, module leader and the control system architect resulted in iterative improvements until the final design and equipment specifications of the proposed experimental set-up was agreed upon.

The set-up was designed to have two main controlled variables (CVs), CSTR level and reactor temperature, with more than one manipulated variable (MV) options for control. The level control loop is highly responsive which is hard to control, while the temperature control loop via the jacket is very slow in comparison. Students were now required to tune the controller to optimise the conversion of the reaction. This enables students to see the direct connection between reaction engineering and 
systems control in a reactor which greatly enhances the impact and relevance of the experiment.

The procurement and construction process influenced the design process iteratively. As both the physical limitations and capabilities of the teaching equipment came to the fore, amendments could be made to the design. For instance, the controls system architect pointed out that providing students with the option of multiple control strategies such as using different MVs or testing different tuning rules for a single CV can easily be implemented by configuring the control system. This inspired the designers to incorporate this idea in their design, thus increasing the flexibility in experimentation (Construction $\rightarrow$ Design). The value of an advanced PD framework also became clear in the Beta testing stage where the responsible student recommended adding pumps to charge the feed tanks, which improved usability and intrinsic safety of the set-up (Beta-Testing $\rightarrow$ Design)

Phase $C$ - experimental set-up construction, commissioning and alpha-test

The construction of the equipment was led by a GTA with significant knowledge of building research-grade experimental rigs together with a team of $2^{\text {nd }}$ and $3^{\text {rd }}$ year undergraduates. The experimental set-up and its P\&ID are shown in Figure 6. A current $4^{\text {th }}$ year student was the architect of the software for the rig. His knowledge of the previous systems control experiment together with his experiences as a learner influenced his design. He followed a student-centric design approach to make the system easily accessible for a student operator, whilst retaining operator flexibility and simulating real industrial systems. The designed interface is based on layouts for industrial Supervisory Control and Data Acquisition (SCADA) systems (Figure 7), showing real-time output from any controller or sensor. A trending function allows 
visualization of controller output variation with error and time. To promote intellectual engagement, students have the flexibility to implement their own control loops, giving them freedom to explore the design space.

The construction process also influenced the project conception and vice versa as the choice of hardware or control system design possibilities shaped the creation of an authentic learning environment. This took the form of sourcing industrial grade components while re-evaluating module delivery given the newly emerging set-up (Conception $\rightarrow$ Construction). Feedback from post-delivery also improved the construction process. For example, students identified flaws in the pump calibration process which affected operation. The control systems architect and student betatester then developed and tested a fix which enabled students to input their own pump calibration curves (Beta-Testing $\rightarrow$ Construction).

\section{Phase $D$ - beta testing}

Beta testing of the project involved determining the feasibility of the overall project, operational instructions, and the operational envelope of the equipment. A current $2^{\text {nd }}$ year student not involved in the design itself tested a range of process conditions such as reactant concentrations, flowrates and CSTR levels to map out the design space. The tests helped to validate that the rig was indeed able to perform as intended and provided feedback to improve associated teaching material. This approach helps to identify operational issues that a student operator (who is at a similar academic maturity as the beta-tester) might face such as ambiguities in the set-up or unexpected design/safety limitations (Beta-Testing $\rightarrow$ Construction, Teaching Material).

Phase E - roll-out to students 
A key component of the roll-out to students is the hand-out that is provided as this serves as the primary reference for students working on the project. Improved versions of the hand-out following beta-testing were written by the beta-tester and the GTA, and approved by the module leader. This approach avoids communication issues because of the generation gap between students and educators. Students involved in the module development would help with training the assigned GTA. They were able to share the student-centric and pedagogical elements of the set-up which aid the GTA and/or enhance the student experience (Pre-Module Activities $\rightarrow$ Module Delivery). As the module design team were readily available throughout the teaching term, feedback from students or issues could be addressed quickly, e.g. the pump calibration issue previously discussed in phase $\mathrm{C}$ (Roll-Out $\rightarrow$ Construction). This also meant that the reliability of the set-up increased over time.

The project has been on offer since Autumn 2016, and the student feedback for the time since confirmed that not only was the new set-up easy to use, it also helped their understanding of process control and reaction engineering. They appreciated that while the new project was certainly challenging regards time management and teamwork, it was also engaging. The general tone of the feedback changed from criticism of the intellectual stimulation to constructive proposals for further improvement. This shift is a strong signal that the new module design is a step in the right direction. Not only did students value the additional time dedicated towards an in-depth study of one research question, they also recognized the industrial relevance and authenticity built into the projects.

Furthermore, feedback highlighted a disconnect between the controller tuning approach as designed for this project and how it is taught in lectures. As a result, the project was reconceptualised to harmonise theory and its application in an authentic 
setting. The project has been adapted with new actuators and an updated control programme to allow students to tune the controller while testing different tuning rules as well as implementing feed-forward control. This example clearly demonstrates the interaction among different phases of the PD process with the roll-out phase, i.e. conception, design, and construction / procurement.

\section{Evaluation}

The Knowledge Lab module designed on the principles of PD was rolled out to students during the Autumn Term of 2016. Figure 8 shows UG SOLE results over three consecutive years from 2015, which was the last year the previous approach had been taught. Overall satisfaction dropped in the implementation year, which textural comments mainly put down to teething troubles with the equipment. Although numerically intellectual stimulation remained broadly the same, no text comments indicating the previously voiced disengagement were received.

In 2017 , the module received a $35 \%$ increase in overall student satisfaction, a $54 \%$ increase in feedback quality, and a $17 \%$ increase in intellectual stimulation compared to 2015 . More than $80 \%$ of students found the module intellectually stimulating in 2017 compared to $69 \%$ in 2016, and $65 \%$ in 2015 . The evidence presented here clearly points out that initial operational issues notwithstanding, student perception of the Knowledge Lab has significantly improved as a direct result of an advanced PD approach.

\section{Conclusion}

The described module design process demonstrates how advanced PD can be implemented for developing experiential learning modules. Involving students into the module design process results in enhanced learner outcomes since the content 
is structured in a highly student centric manner. From concept to roll-out, student involvement has made the experiment more accessible and safer whilst not compromising on academic rigour. As the development process exposes students to the complexity of designing, constructing and testing experimental equipment, it serves as a microcosm of hands-on engineering practice where important skills (such as specifying appropriate components, developing data acquisition and control systems and machining parts) can be learned within a university environment - an experience that is usually reserved for the post-graduation working life. Suitable guidance from academic members of staff can ensure that the designed module still meets teaching requirements and is pedagogically sound. This reduces the operational workload on staff members allowing them to focus on intellectual engagement with the students, who feel a sense of ownership for the work that they helped to develop, which is one of the cornerstones of the 'students as partners' philosophy in higher education.

\section{Acknowledgements}

The authors would like to gratefully acknowledge contributions from Angus Crake, Kyriacos Nikiforou, Robert Clark, Fintan O'Connor, Yanshen Zhu, Jonathan Ball, Parth Shah, and Andrew Macey to the design, construction, beta-testing, and roll-out of the PD approach and associated equipment.

\section{References}

Amolins, M.W., Ezrailson, C.M., Pearce, D.A., Elliott, A.J. and Vitiello, P.F., 2015. Evaluating the effectiveness of a laboratory-based professional development program for science educators, Adv. Physiol. Edu. 39, 341-351.

Bovill, C., 2011. Student Engagement: Students as active partners in shaping their learning experience. Int. J. Acad. Dev. 16, 133-145.

Bovill, C., Bulley, C.J., 2011. A model of active student participation in curriculum 
design : exploring desirability and possibility, in: In C. Rust (Ed.), Global Theories and Local Practices: Institutional, Disciplinary and Cultural Variations. Oxford Brookes University, Oxford, pp. 176-188.

Chen, W., Shah, U., Brechtelsbauer, C., 2016. The discovery laboratory - A studentcentred experiential learning practical: Part I - Overview. Educ. Chem. Eng. 17, 44-53.

Farahbakhsh, K., Stiver, W., 2007. Student-Led Design, Build, Testing and Usage of in-Course Experimental Laboratories, in: American Society for Engineering Education. p. 1.

Glassey, J., Novakovic, K., and Parr, M., 2013 Enquiry based learning in chemical engineering curriculum supported by computer aided delivery, Educ. Chem. Eng. 8, 87-93.

Huppatz, C., 1996. The essential role of the student in curriculum planning. Med. Educ. 30, 9-13.

Könings, K.D., Seidel, T., van Merriënboer, J.J.G., 2014. Participatory design of learning environments: Integrating perspectives of students, teachers, and designers. Instr. Sci. 42, 1-9.

Lu, C.Y., Nguyen, Q., Ersin, O.H., 2015. Active Student Engagement. Am. J. Pharm. Educ. 79, 1.

Salter, D., Pang, M., Sharma, P., 2009. Active Tasks to Change the Use of Class Time within an Outcomes Based Approach to Curriculum Design. J. Univ. Teach. Learn. Pract. 6, 27-38.

Tärnvik, A., 2007. Revival of the case method: A way to retain student-centered learning in a post-PBL era. Med. Teach. 29.

Tyma, A.W., 2009. Pushing Past the Walls: Media Literacy , the "Emancipated" Classroom, and a Really Severe Learning Curve 1. J. Commun. 3, 891-900.

Walker, C., 2008. Teaching Policy Theory and its Application To Practice Using Long Structured Case Studies: An Approach that Deeply Engages Undergraduate Students. Int. J. Teach. Learn. High. Educ. 20, 214-225.

Weimer, M., 2002. Learner-Centered Teaching: Five Key Changes to Practice. Jossey-Bass, San Francisco, CA.

Wright, G.B., 2011. Student-Centered Learning in Higher Education. Int. J. Teach. Learn. High. Educ. 23, 92-97. 
(a)

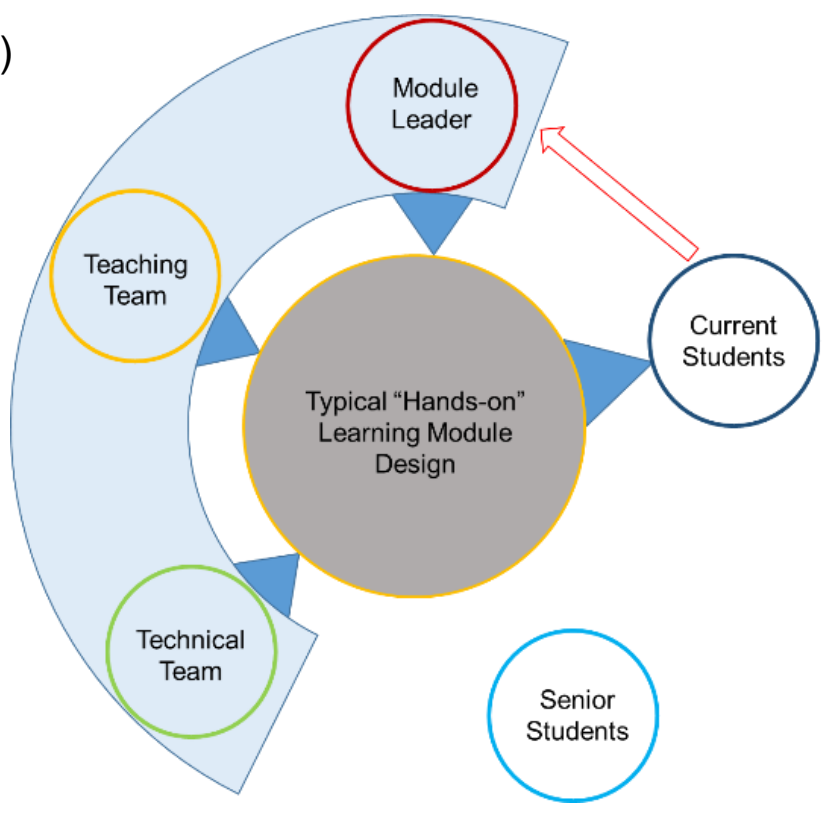

(b)

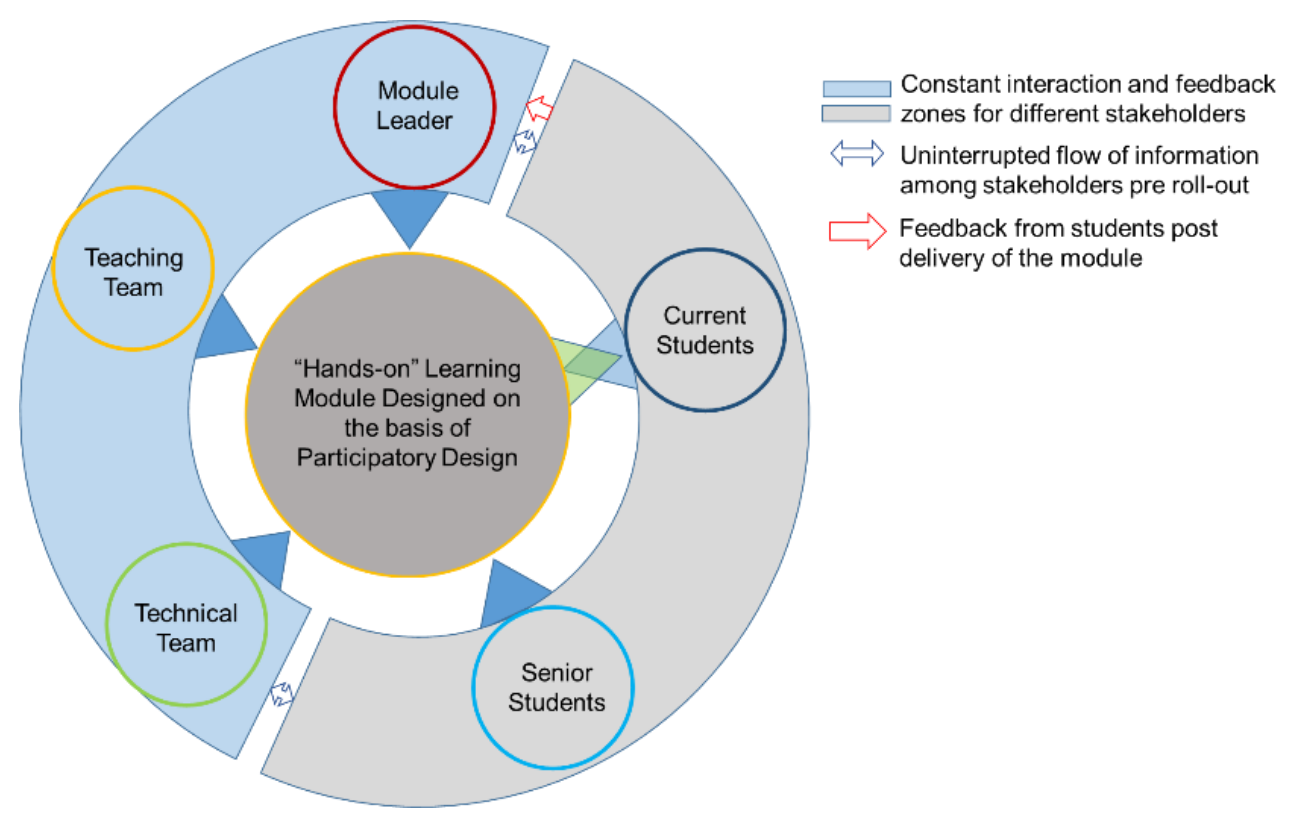

Figure 1: Stakeholder involvement in typical (a) and PD based module design (b) 

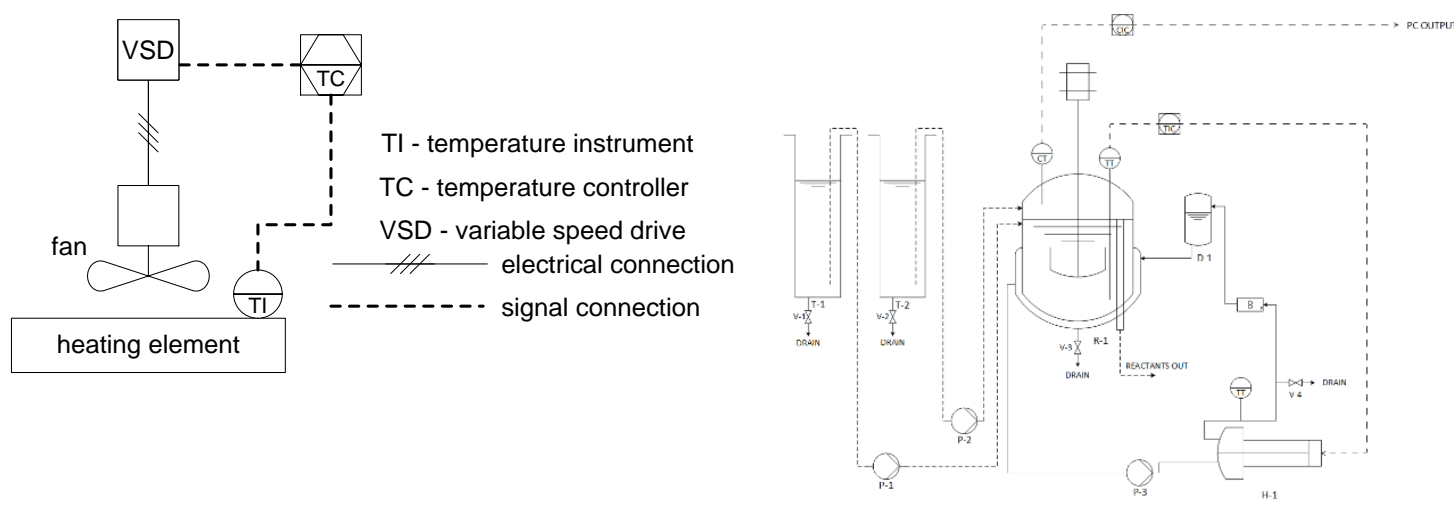

Figure 2: P\&ID for Previous Systems Control Set-up (Left) and CSTR Set-up (Right)

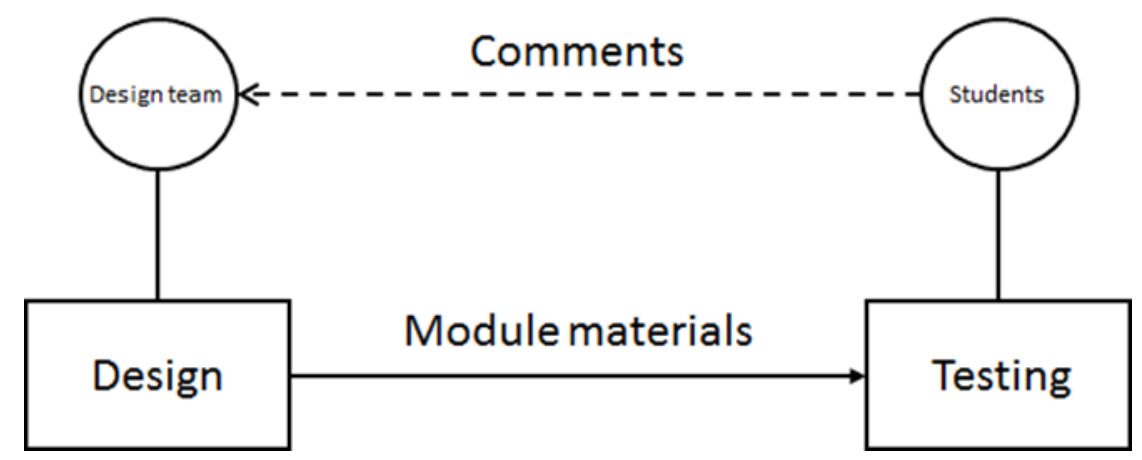

Figure 3: Feedback mechanism during module development 


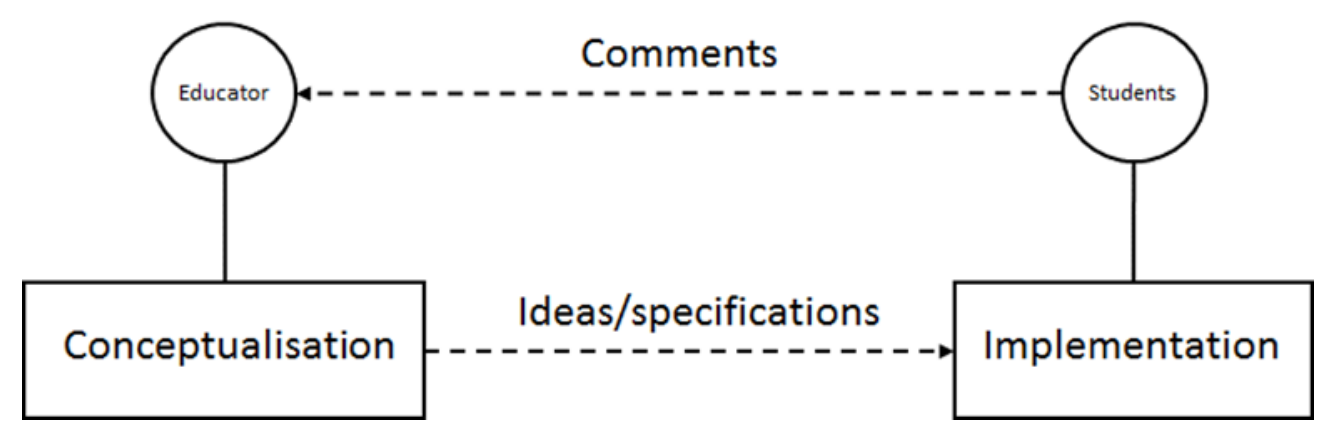

Figure 4: Feedback mechanism during the overall design process

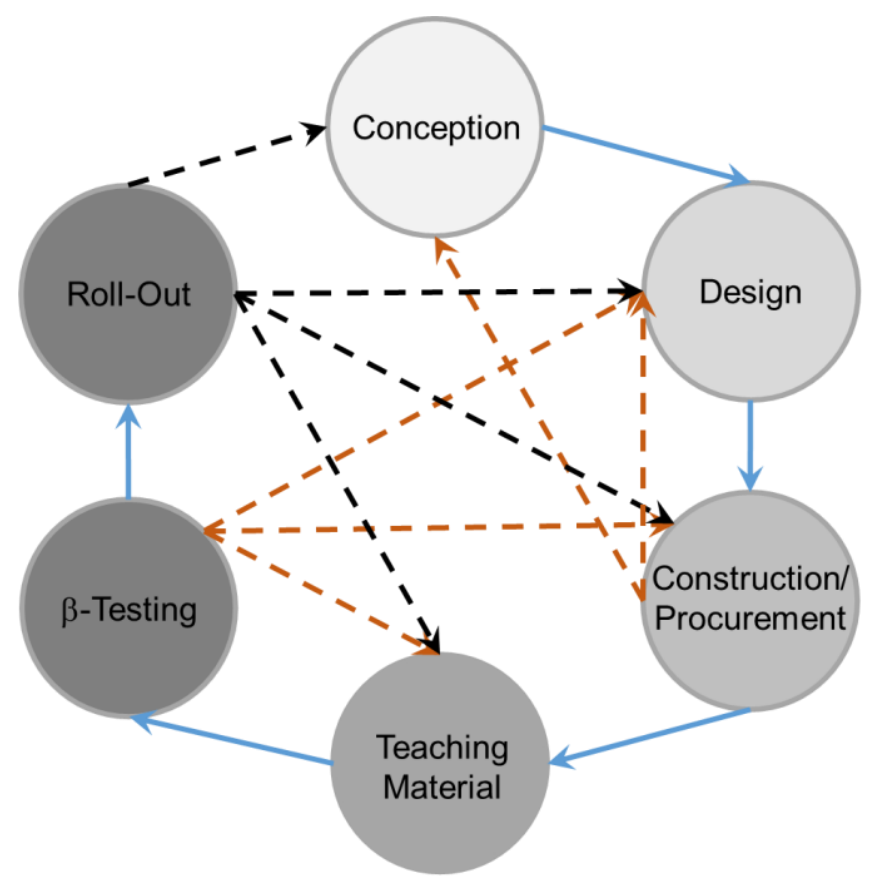

- - Feedback post delivery by the student and teaching team

- - - Feedback pre delivery by all the stakeholders

Figure 5: "Hands-on" learning module design process employed in this study 

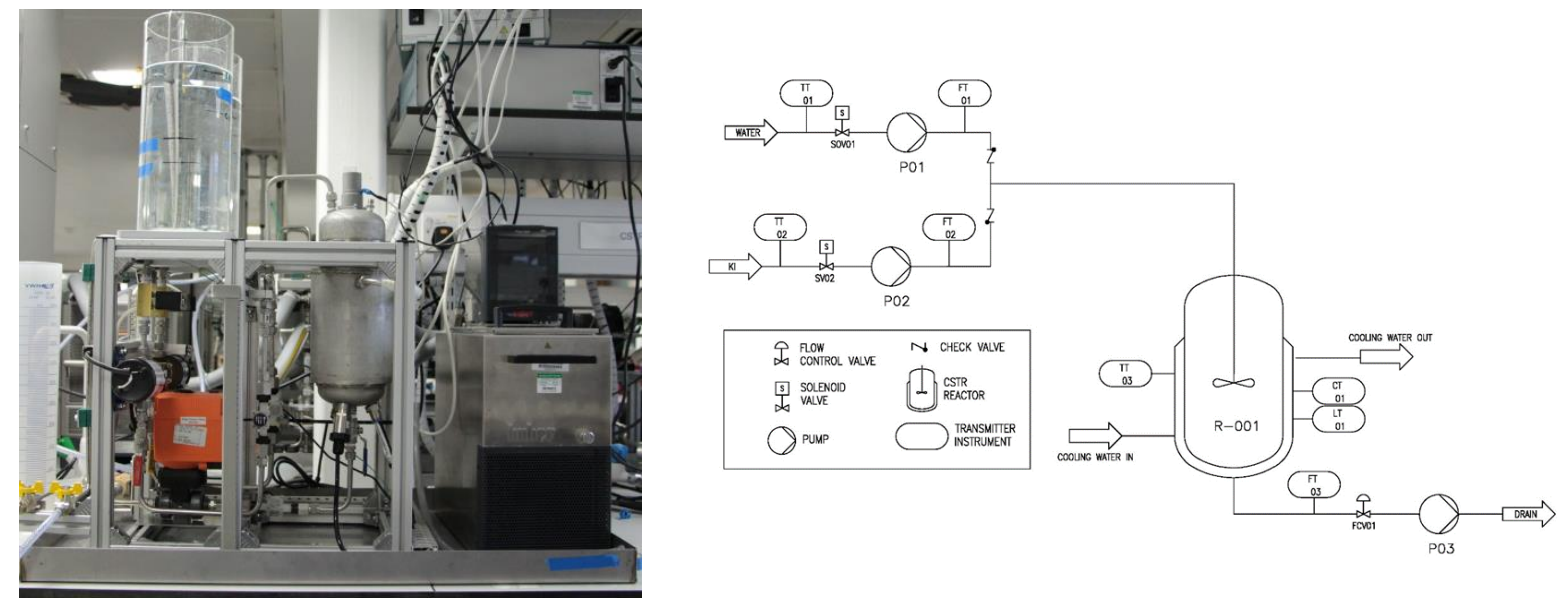

Figure 6: Image of the experimental set-up (left) and P\&ID (right)

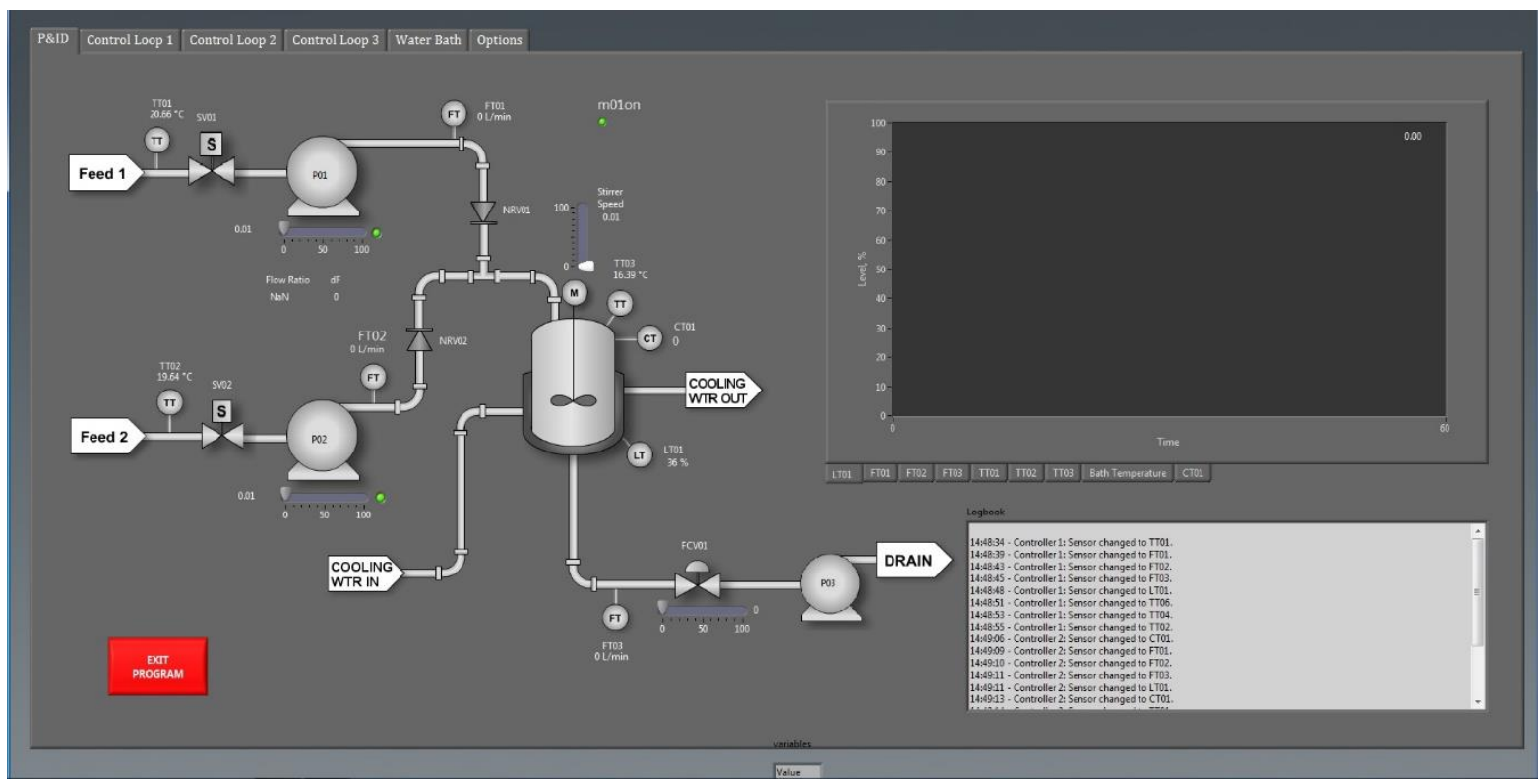

Figure 7: Screenshot of SCADA Interface 


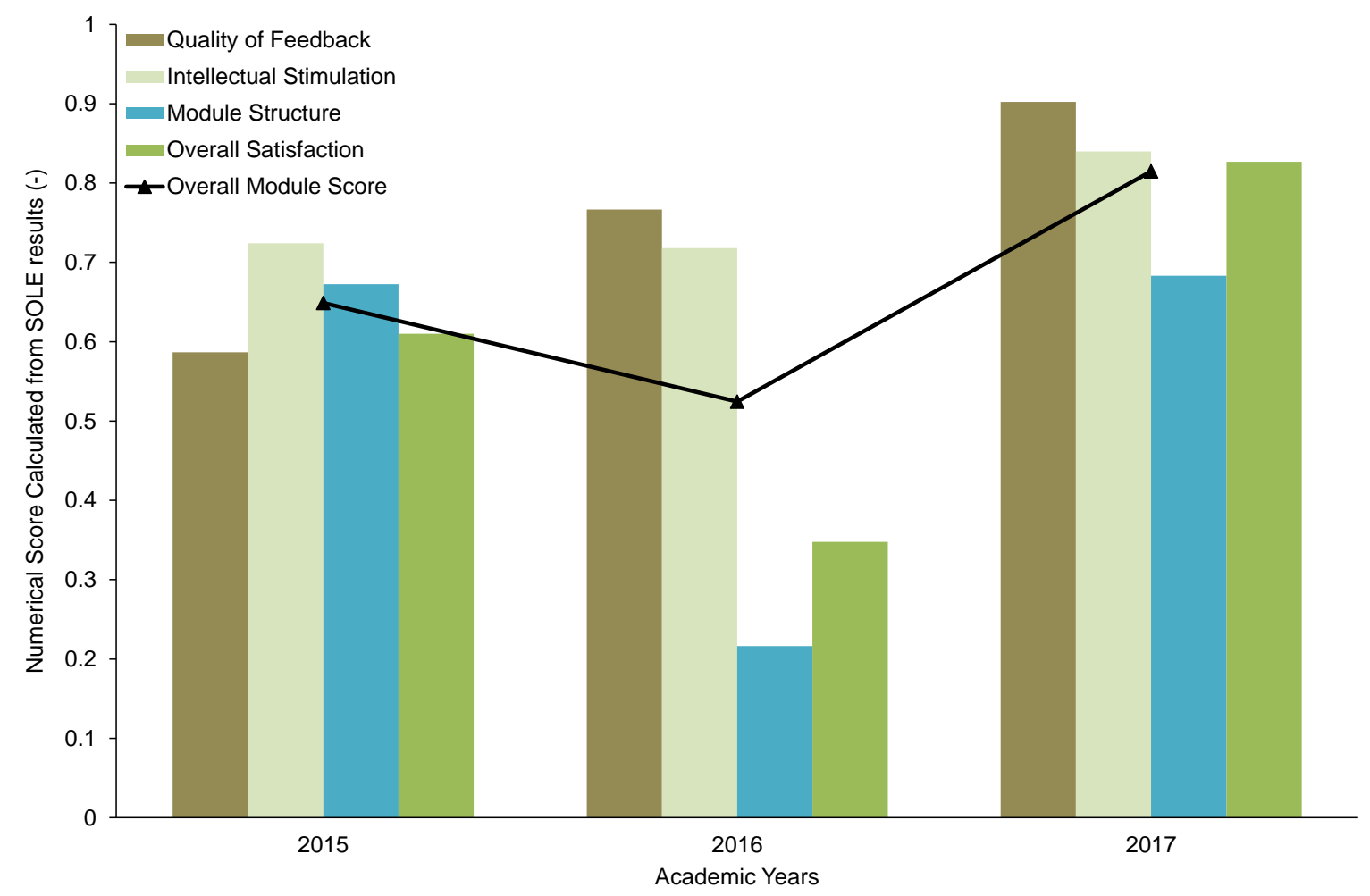

Figure 8: Knowledge Lab UG SOLE results 